\title{
Sinopse das espécies neotropicais do grupo nitida do gênero Apenesia (Hymenoptera, Bethylidae)
}

\author{
Magno S. Ramos ${ }^{1}$, Brenda O. P. de Araújo² \& Celso O. Azevedo \\ 1. Programa de Pós-graduação em Biologia Animal, Universidade Federal do Espírito Santo, Av. Marechal Campos 1468, Maruípe, \\ 29043-090 Vitória, ES, Brasil. (magnosuprani@gmail.com) \\ 2. Departamento de Biologia, Universidade Federal do Espírito Santo, Av. Marechal Campos 1468, Maruípe, 29040-090 Vitória, ES, \\ Brasil. (bethylidae@gmail.com)
}

\begin{abstract}
Synopsis of Neotropical species of nitida group genus Apenesia (Hymenoptera, Bethylidae). Two species are described and illustrated: Apenesia quelata sp. nov. and A. trivisa sp. nov. New geographic records and data on morphostructural variation of A. membranaceus Lanes \& Azevedo, 2004, A. paraensis Kieffer, 1910, A. quadrata Evans, 1963, A. serrulata Azevedo \& Batista, 2002, e A. williamsi Evans, 1966 are provided. Two species are synonymyzed: A. laticeps Evans, 1963 as junior synonym of A. quadrata Evans, 1963; A. truncaticeps (Kieffer, 1910) as junior synonym of A. paraensis Kieffer, 1910. The female of A. quadrata is described and illustrated for the first time. Key to the species of the nitida species-group based on males is provided.
\end{abstract}

KEYWORDS. Synonyms, new species, key, taxonomy.

RESUMO. São descritas e ilustradas duas espécies: Apenesia quelata sp. nov. e A. trivisa sp. nov. São fornecidos registros geográficos novos e dados sobre variações morfoestruturais de A. membranaceus Lanes \& Azevedo, 2004, A. paraensis Kieffer, 1910, A. quadrata Evans, 1963, A. serrulata Azevedo \& Batista, 2002 e A. williamsi Evans, 1966. Duas espécies são sinonimizadas: A. laticeps Evans, 1963 como sinônimo júnior de A. quadrata Evans, 1963; A. truncaticeps (Kieffer, 1910) como sinônimo júnior de A. paraensis Kieffer, 1910. A fêmea de A. quadrata é descrita e ilustrada pela primeira vez. É fornecida chave de identificação para as espécies do grupo nitida, baseada em machos.

PALAVRAS-CHAVE. Sinonímias, espécies novas, chave, taxonomia.

O gênero Apenesia Westwood, 1874 foi originalmente descrito apenas com base em fêmeas. Evans (1963) comentou que os machos de Apenesia foram erroneamente determinados como Propristocera Kieffer, 1905, Cleistepyris Kieffer, 1910 e Dipristocera Kieffer, 1914. Isso ocorreu em virtude do dimorfismo sexual que existe nas espécies: os machos são escuros, robustos e macrópteros, conquanto que as fêmeas são delgadas e ápteras.

As espécies que compõem o grupo nitida (Bethylidae, Pristocerinae, Apenesia) têm como características principais a presença de um dente apical distinto na mandíbula, sendo os demais fundidos numa lâmina; clípeo curto com ápice simples ou bidentado; fronte polida, com pontos pequenos; carena anterior no disco pronotal; metassomo peciolado; genitália com parâmeros expandidos apicalmente; e edeago geralmente terminando em dois pares de lobos delgados (Evans, 1963). Esse grupo é composto atualmente por 12 espécies, todas restritas à América do Sul (Evans, 1963): Apenesia auricula Lanes \& Azevedo, 2004, A. hepatica Corrêa \& Azevedo, 2006, A. laticeps Evans, 1963, A. lobata Azevedo \& Batista, 2002, A. membranaceus Lanes \& Azevedo, 2004, A. nitida (Kieffer, 1910), A. paraensis Kieffer, 1910, A. quadrata Evans, 1963, A. serrulata Azevedo \& Batista, 2002, A. subangulata Azevedo \& Batista, 2002, A. truncaticeps (Kieffer, 1910) e A. williamsi Evans, 1966.

Este trabalho teve como objetivo reconhecer e delimitar as espécies pertencentes ao grupo, descrever duas espécies novas e propor uma chave de identificação atualizada baseada em machos. Além disso, foram ampliadas informações taxonômicas e de distribuição geográfica.

\section{MATERIAL E MÉTODOS}

O material analisado foi proveniente das seguintes coleções (curadores entre parenteses): BPBM, Bernice P. Bishop Museum, E.U.A. (A. Ramsdale); CNCI, Canadian National Colection of Insects, Canadá (J. T. Huber); CUIC, Cornell University, E.U.A. (E. R. Hoebecke); IBGE, Instituto Brasileiro de Geografia e Estatística, Brasil (B. Dias); INPA, Instituto Nacional de Pesquisas da Amazônia, Brasil (J.A. Rafael); MACN, Museo Argentino de Ciencias Naturales Bernardino Rivadavia, Argentina (A. Roig Alsina); MNRJ, Museu Nacional do Rio de Janeiro, Brasil (M. A. Monné); MNHNP, Museo Nacional del Historia Natural del Paraguay, Paraguai (Bolivar Garcete); MPEG, Museu Paraense Emílio Goeldi, Brasil (A. Harada); MZSP, Museu de Zoologia de São Paulo, Brasil (C. R. F. Brandão); UFES, Universidade Federal do Espírito Santo, Brasil (C. O. Azevedo); UCDC, The Bohart Museum of Entomology, University of California, Davis, Califórnia, E.U.A. (S. L. Heydon); USNM, National Museum of Natural History, E.U.A. (T. Schultz, D. Furth); ZMHB, Zoologisches Museum an der HumboldtUniversität zu Berlin, Alemanha (F. Koch).

Foram analisados e ilustrados os holótipos das espécies do grupo nitida. A chave de identificação proposta foi baseada principalmente em caracteres das genitálias. 
Para tanto, os indivíduos tiveram suas genitálias extraídas. Os mesmos foram mantidos aproximadamente por uma hora em amoníaco visando o seu amolecimento. Uma vez dissecadas, as genitálias foram diafanizadas com uma solução de hidróxido de potássio $(\mathrm{KOH}) 10 \%$. As genitálias foram guardadas em tubos de genitália de insetos.

Material-tipo examinado.

Apenesia auricula Lanes \& Azevedo, 2004. Holótipo macho: BRASIL, Am[azonas]: Manaus, Reserva Campina, 08-19.VI.1992, adesiva [= stick trap], Vidal col. (INPA) (Figs 1-4).

Apenesia hepatica Corrêa \& Azevedo, 2006. Holótipo macho: BRASIL, Bahia: Sarapiranga, Reserva de Sarapiranga, $12^{\circ} 33^{\prime} 58,5^{\prime}$ 'S, $38^{\circ} 02^{\prime} 57,2^{\prime \prime} \mathrm{W}, 16-19$.VII.2001, armadilha Malaise, M. T. Tavares e eq. col. (MZSP) (Figs 5-7).

Apenesia lobata Azevedo \& Batista, 2002. Holótipo macho: BRASIL, Acre: P[ar]q[u]e Nac[ional da] Serra [do] Divisor, [ponto] norte 3, 12, 13.XI.1996, arm[adilha] Malaise, E. F. Morato col. (UFES) (Figs 8-11).

Apenesia nitida (Kieffer, 1910). Holótipo macho: PERU, Cuzco: Conispata - Ebene, 1000m, 03.XII.1900, Garlepp S. V. col. (ZMHB \#197). (Figs 17-19).

Apenesia subangulata Azevedo \& Batista, 2002. Holótipo macho: BRASIL, Acre: P[ar]q[u]e Nac[ional da] Serra [do] Divisor, [ponto] norte 3, 12, 13.XI.1996, arm[adilha] Malaise, E. F. Morato col. (UFES) (Figs 34-36).

Os termos das estruturas seguem aqueles adotados por Evans (1963). Os termos referentes à textura do integumento seguem HARRIs (1979). Foram utilizadas as seguintes medidas: comprimento da asa anterior (LFW); comprimento da cabeça (LH); largura da cabeça (WH); largura da fronte (WF); comprimento do olho (HE); linha ocelar-ocular (OOL); largura do triângulo ocelar (WOT); diâmetro do ocelo anterior (DAO); linha do vértice-ocular (VOL).

A análise inicial dos exemplares do grupo nitida baseou-se na chave de identificação proposta por EvANS (1963). A partir da análise dos holótipos, do estudo dos espécimes e da revisão da bibliografia, foi elaborada uma chave nova de identificação para machos, considerando corpo e genitália, de acordo com as variações existentes.

Os termos colocados entre colchetes, presentes tanto no material examinado quanto aqui estudados, referem-se às palavras que estavam abreviadas nas etiquetas de identificação dos exemplares. Por outro lado, aquelas palavras que continham erro de grafia foram colocadas entre chaves. Os nomes dos respectivos curadores das coleções presentes neste trabalho foram colocados entre parênteses.

Os caracteres referentes ao grupo nitida foram importados para DELTA versão editor (DEscription Languange TAxonomy) de DALLwiTz (1980) e DALLwiTZ et al. (1999) e usado para gerar as descrições das espécies usando DELTA confor de DALLwITZ (1980) e DALLwiTz et al. (1993).

\section{RESULTADOS E DISCUSSÃO}

Foram reconhecidas sete espécies pertencentes ao grupo nitida, sendo cinco previamente descritas e duas espécies novas. Considerando-se que foram propostas as sinonímias de A. laticeps Evans, 1963 com A. quadrata Evans, 1963 (Figs 24-27) e A. truncaticeps (Kieffer, 1910) com A. paraensis Kieffer, 1910 (Figs 20-23), o número de espécies neotropicais do grupo permanece o mesmo (12).

Chave para machos do grupo de espécies nitida da Região Neotropical

1. Clípeo com lobo mediano angulado ou subangulado (Figs 1, 5, 17, 28, 40) ........................................ 2

1'. Clípeo com lobo mediano truncado, subtruncado ou bidentado (Figs 20, 31, 37) ........................... 8

2. Parâmero não fundido ao basiparâmero (Figs 3, 7, 22, 26)

2'. Parâmero fundido ao basiparâmero (Figs 14, 36) ..... 7

3. Edeago com um par de lobos apicais (Fig. 19) ......... 4

3'. Edeago com dois pares de lobos apicais (Figs 22, 26, 30,33)

4. Parâmero com região mediana estreitada, ramo ventral do dígito fino e curvado, com ápice arredondado (Fig. 19) .......................... A. nitida (Kieffer, 1910)

4'. Parâmero sem constrição na região mediana (Fig. 7); ramo ventral do dígito dilatado, com ápice truncado (Fig. 7) ......... A. hepatica Corrêa \& Azevedo, 2006

5. Parâmero sem dobra ventral na região basal e com concavidade pronunciada na margem apical (Fig. 30); lobo lateral do edeago dividido em duas regiões por septo mediano; margem basal da basivolsela retilínea com cantos arredondados (Fig. 30) ........

A. quelata sp. nov.

5'. Parâmero com dobra ventral na região basal e com concavidade pouco profunda na margem apical (Figs 3, 42); lobo lateral do edeago sem septo mediano; margem basal da basivolsela arredondada (Figs 3, 42, 43) .

6. Margem apical do parâmero com concavidade irregular (Fig. 3); edeago com lobo mediano ligeiramente menor que lobo lateral (Fig. 3) ....

..... A. auricula Lanes \& Azevedo, 2004 (Figs 1-4)

6'. Margem apical do parâmero com concavidade regular (Fig. 40); edeago com lobo mediano muito menor que lobo lateral (Figs 42, 43)

A. williamsi Evans, 1966

7. Lobo lateral do edeago laminar e com ápice ligeiramente dobrado para dentro (Fig. 14)

.......... A. membranaceus Lanes \& Azevedo, 2004

7'. Lobo lateral do edeago longo e fino no ápice (Fig. 36) ............ A. subangulata Azevedo \& Batista, 2002

8. Concavidade da margem apical do parâmero ligeiramente irregular (Fig. 11); edeago com um par de lobos apicais (Fig. 11)

A. lobata Azevedo \& Batista, 2002

8'. Concavidade da margem apical do parâmero uniformemente regular (Figs 22, 26, 33, 39); edeago com mais de um par de lobos apicais (Figs 22, 26, 33,39 9

9. Lobo lateral do edeago com margem lateral serrulada, menor que lobo mediano (Fig. 33)

A. serrulata Azevedo \& Batista, 2002

9'. Lobo lateral do edeago sem margem lateral serrulada, tão longo ou mais longo que lobo mediano (Figs 22, 26, 39) 10

10. Edeago com lobo lateral com placas dorsal, mediana e ventral (Fig. 39) A. trivisa sp. nov. 
10'.Edeago com lobo lateral formado por placa única (Figs 22, 26)

11. Edeago com lobo lateral de ápice pontiagudo (Fig. 26) A. quadrata Evans, 1963

11'.Edeago com lobo lateral de ápice arredondando ou ligeiramente côncavo (Fig. 22)..... A. paraensis Kieffer, 1910

\section{Apenesia membranaceus Lanes \& Azevedo, 2004 (Figs 12-16)}

Essa espécie foi registrada para os estados do Amazonas e Amapá no Brasil por LANES \& AzEVEdo (2004) e agora é citada pela primeira vez para o Suriname (Brokopondo). Nenhuma variação morfoestrutural significante foi observada.

Material-tipo examinado. Holótipo ơ. BRASIL, Am[azonas]: Manaus (Reserva 1208), 13.V.1986, armadilha Malaise, B. Klein col. (INPA) (Figs 12-16).

Material adicional examinado: SURINAME, Brokopondo: $1 \sigma^{\prime}$, (Browsberg Nature, Preserved witi creek trail, 4'56'55', N, 5510'53''W, 420 m), 22, 23-VI-1999 (CNCI).

\section{Apenesia paraensis (Kieffer, 1910)}

(Figs 20-23)

Propristocera paraensis KIEFFER, 1910:290, 291. Holótipo Oౌ, localidade-tipo: Brasil, Pará, não encontrado na California Academy of Science.

Cleistepyris truncaticeps KIEFFER, 1910:50. Holótipo O’, localidadetipo: Bolívia, Mapiri, encontrado no ZMHB.

Apenesia truncaticeps; Evans (1963):343, 344, figs 117, 119, 123, 124. Syn. nov.

Propristocera bolivisensis OGLOBLin, 1938:44-48, figs 15, 16. Holótipo O’, localidade-tipo: Bolívia, Santa Cruz, encontrado no MACN. Sinonimizado por Evans, 1963:343.

Esta espécie foi registrada para a Bolívia (Beni, Chuquisaca, Pando e Santa Cruz), para o Peru (Huánuco), Venezuela (Barinitas) e Brasil (Acre, Pará) por Evans (1963); Brasil (Amazonas, Maranhão e Rondônia) por LANES \& AzEVEDO (2004). Agora é citada pela primeira vez para Cochabamba e La Paz na Bolívia.

Variações. Pubescência antenal subereta, sem cerdas rijas e de comprimento cerca de $0,7 x$ maior que a largura do segmento XI; fronte com pontos pequenos, mas conspícuos; disco pronotal com depressão transversal posterior que varia de fraca e rasa em alguns espécimes a forte e profunda em outros, e pode ser mais acentuada dos lados. Mesoscuto com notáulice incompleta.

Comentários. As espécies Apenesia truncaticeps (Kieffer, 1910) e A. paraensis (Kieffer, 1910) compartilham muitos caracteres em comum, tais como clípeo com carena media fraca, disco pronotal com forte carena transversal anterior, mas principalmente aqueles referentes à genitália (Fig. 23). Tais espécies nessa estrutura compartilham parâmero amplamente expandido, com dobra na base, concavidade regular na margem apical do parâmero e lobo lateral do edeado com ápice arredondado. Em função disto, A. truncaticeps foi considera como sinônimo júnior de $A$. paraensis.

Material-tipo examinado. Homeótipo ơ. BRASIL, Pará: Santarém, genitália slide H\#475. [det. por Evans] (USNM) (Figs 20-22).
Material adicional examinado. BRASIL, Rondônia: Fazenda Rancho Grande, $62 \mathrm{~km}$ s. Ariquemes, 1 ơ $^{\curvearrowright}, 12-22 . X I .1991$, M[alaise] T[rap], E. M. Fisher col.; $10^{\prime}, 10^{\circ} 18^{\prime}$ 'S, 62 ${ }^{\circ} 53^{\prime}$ W, 08-20.IV.1997, M[alaise] T[rap], A. C. Rhen \& C. Alexander col.; $1 \sigma^{7}, 11 \mathrm{~km} \mathrm{~s}$. Ariquemes, sweeping on forest trail, 27.XI.1991, S. L. Heydon col. (UCDC); BOLÍVIA, Cochabamba: $67,5 \mathrm{~km}$ E.Vila Tunari (Est[acion] Biol[ógica] Valle del Saito, low land rain forest,

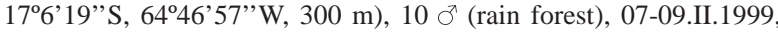
F[light] I[nterception] T[rap]; 40 , (Univ[ersidad] San Simon, low land rain forest), 09-13.II.1999, F[light] I[nterception] T[rap], F.

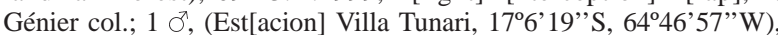
05-07.II.1999, F[light] I[nterception] T[rap], R. S. Hanley col.; 1 0', (Vila Tunari, 06 $59^{\prime} 54^{\prime \prime} \mathrm{S}, 65^{\circ} 26^{\prime} 10^{\prime \prime} \mathrm{W}, 325 \mathrm{~m}$ ), 04 06.XI.2000, M[alaise] T[rap]; $10^{7}$, (trop[ical] for[est], $\left.16^{\circ} 54^{\prime} 55^{\prime \prime} \mathrm{S}, 65^{\circ} 22^{\prime} 06^{\prime \prime} \mathrm{W}\right), 05-11 . X I .2001$, M[alaise] T[rap]; 3 o', 15.III.2001, M[alaise] T[rap]; 3 o', 06.X.2001, M[alaise] T[rap];

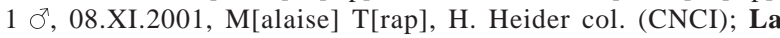
Paz: Noryungas, (Coroico, Cloud For[est], El Bagante, B-03, 1500 m), 4 Ơ, 18.IV.1997, L. Masner s. s. col. (CNCI).

\section{Apenesia quadrata Evans, 1963 \\ (Figs 24-27, 44-47)}

Apenesia quadrata Evans, 1963:344, 345, est. 10, fig. 121. Holótipo ơ, localidade-tipo: Brasil, Minas Gerais, Diamantina, encontrado no CUIC.

Apenesia laticeps Evans, 1963:345-347, fig. 122. Holótipo ơ', localidade-tipo: Brasil, Minas Gerais, Lassance, encontrado no CUIC (\#3882) (Fig. 27). Syn. nov.

Esta espécie foi registrada para os estados do Amazonas por LANES \& AzEVEDo (2004), Espírito Santo por CORRÊA \& AZEVEDo (2006) e Minas Gerais por EvAns (1963) no Brasil e agora é citada pela primeira vez para o Distrito Federal (Brasil) e Central Capiatá (Paraguai).

Variações. Mesoscuto com notáulice incompleta; disco propodeal com carena discal mediana completa; parâmero com depressão na margem apical do parâmero maior, com formato regular; lobo mediano do edeago do mesmo tamanho ou nitidamente menor que o lateral; lobo lateral do edeago com diferentes graus de curvatura, podendo ser mais fechados ou mais abertos.

Comentários. Segundo Evans (1963), A. quadrata e A. laticeps diferem basicamente quanto aos caracteres do ápice do edeago, sendo estes relacionados à altura e a espessura do lobo mediano em comparação ao lobo lateral.

De acordo com a descrição de Evans (1963), A. laticeps (Fig. 27) possui edeago com lobo lateral aproximadamente tão delgado quanto em A. quadrata e mais curto que na mesma. Por outro lado, a espécie $A$. quadrata, possui edeago com lobo mediano tão longo e delgado quanto o lobo lateral, sendo esta até então conhecida somente pelo tipo.

A partir da análise das genitálias dos exemplares de A. laticeps e A. quadrata, ambas de Evans (1963), observou-se que nas duas espécies foram encontrados caracteres, principalmente aqueles relacionados ao lobo lateral e mediano do edeago, que não estavam de acordo com a descrição original. Foram analisados alguns espécimes de A. laticeps que apresentavam o lobo mediano do edeago tão longo quanto o lobo lateral e, além disso, tão delgado quanto em A. quadrata, bem como alguns espécimes de $A$. quadrata que apresentavam o lobo mediano do edeago distintamente mais curto que o lobo lateral do edeago. 

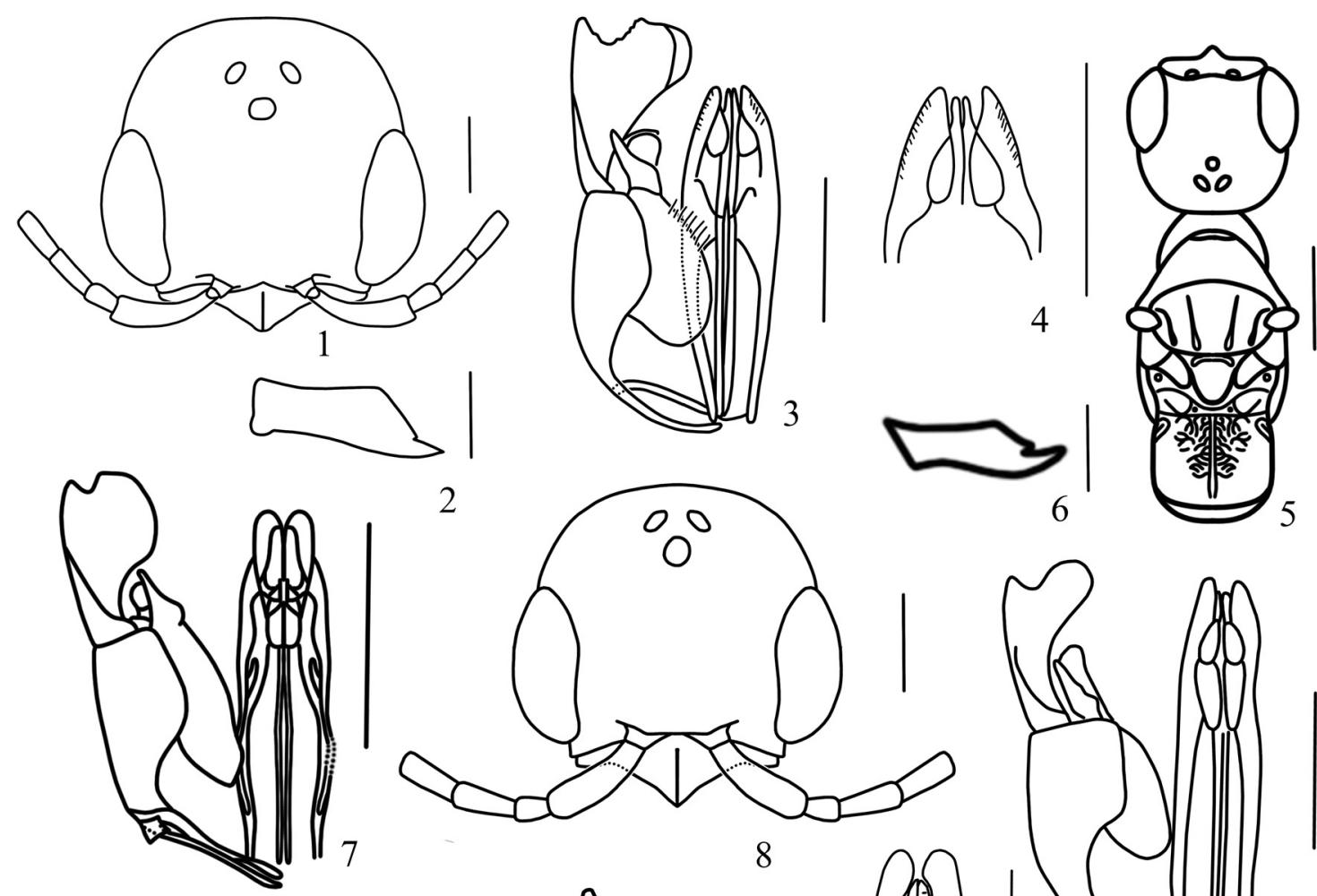

2
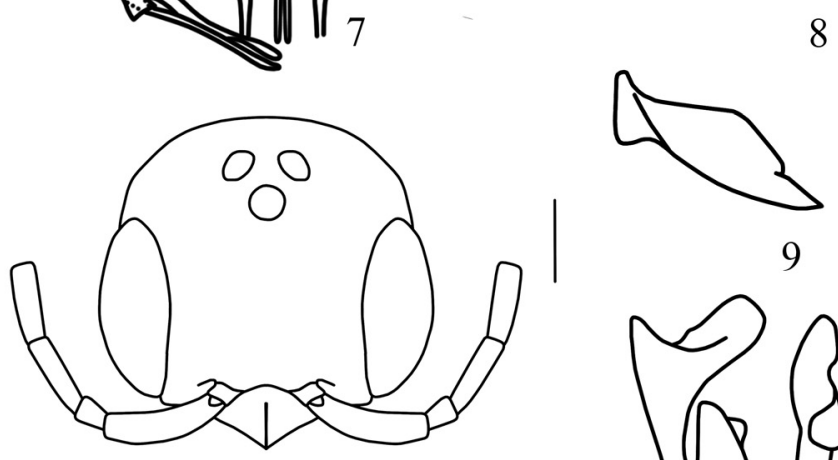

8

12
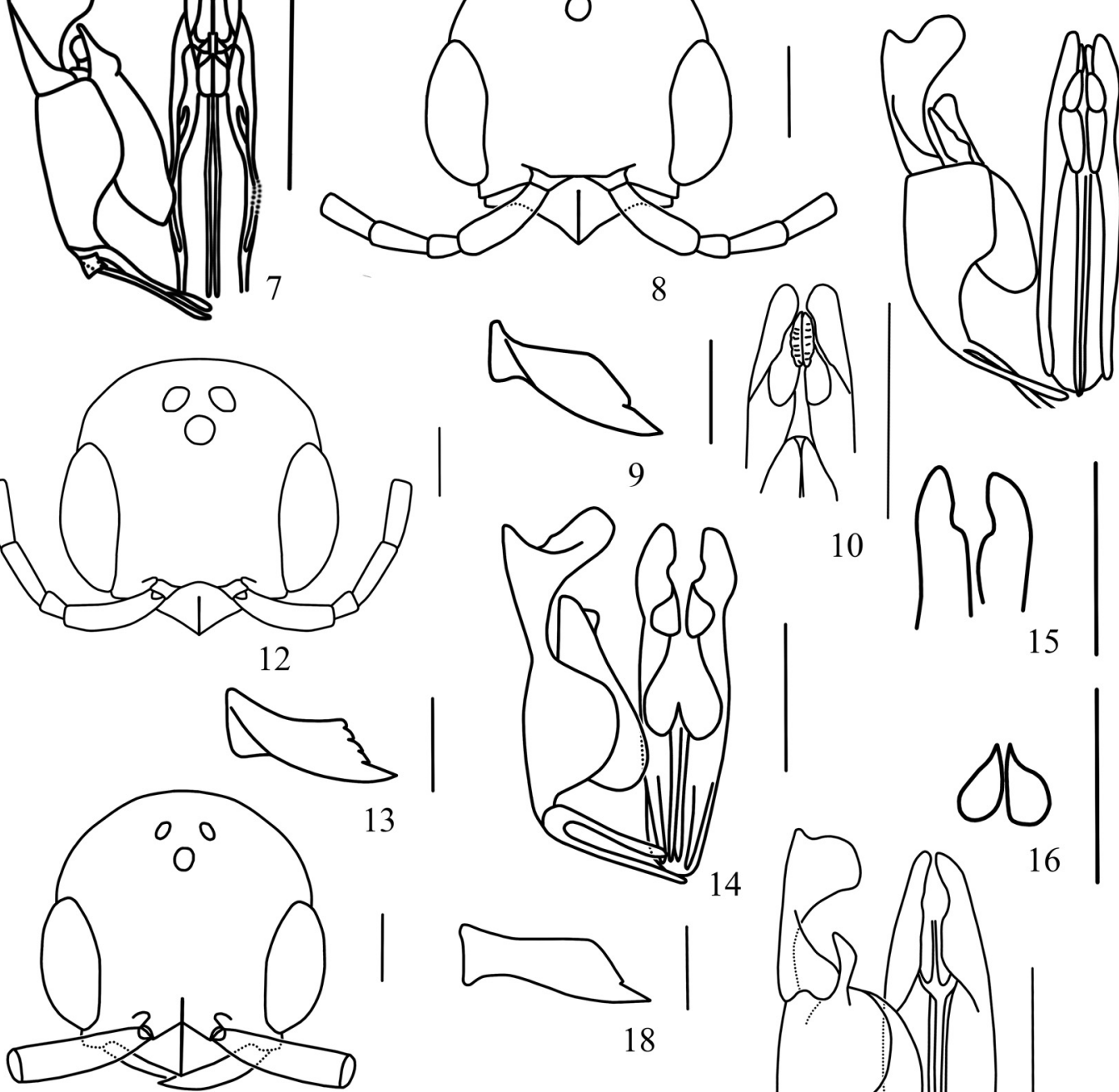

11

17

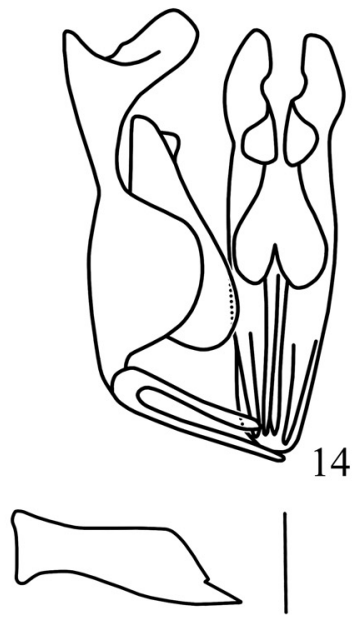

18
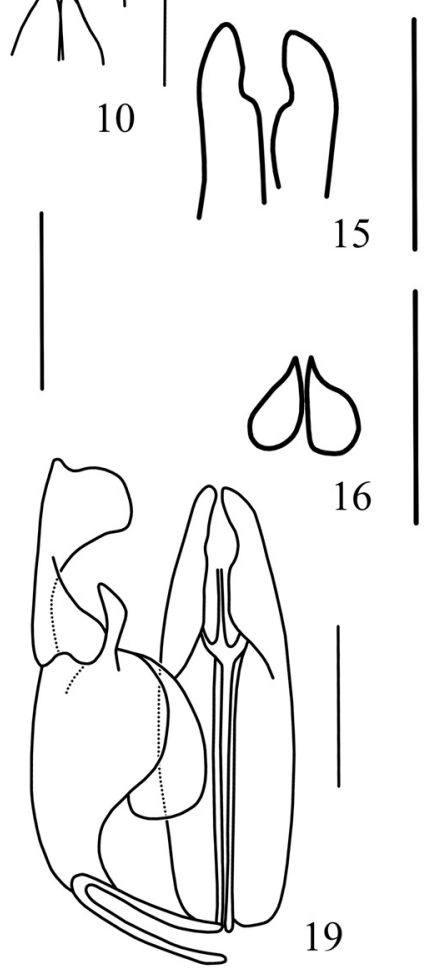

Figuras. 1-19. Apenesia auricula Lanes \& Azevedo, 2004, macho: 1, cabeça, dorsal; 2, mandíbula, frontal; 3, genitália, ventral; 4, lobos apicais do edeago, ventral. A. hepatica Corrêa \& Azevedo, 2006, macho: 5, cabeça e mesossomo, dorsal; 6, mandíbula, frontal; 7, genitália, ventral. A. lobata Azevedo \& Batista, 2002, macho: 8, cabeça, dorsal; 9, mandíbula, frontal; 10, lobos apicais do edeago, ventral; 11, genitália, ventral. A. membranaceus Lanes \& Azevedo, 2004, macho: 12, cabeça, dorsal; 13, mandíbula, frontal; 14, genitália, ventral; 15, lobo dorsal do edeago, ventral; 16, lobo ventral do edeago, ventral. A. nitida (Kieffer, 1910), macho: 17, cabeça, dorsal; 18, mandíbula, frontal; 19, genitália, ventral. Escalas: 0,25 mm. 
Dessa forma, percebeu-se que os caracteres que separam tais espécies, restritos principalmente ao ápice do edeago, são tênues e podem ser interpretados mais como variações intra-específicas contidas em uma única espécie do que como características que as tornariam táxons separados, por este motivo foi proposta A. laticeps como sinônimo júnior de $A$. quadrata.

Além disto, foi encontrada pela primeira vez uma fêmea de Apenesia quadrata coletada em cópula, proveniente da Reserva Ecológica do IBGE, Brasília, DF, a qual é descrita abaixo.

Descrição. Fêmea, comprimento 4,20 mm. Corpo castanho-claro.

Cabeça (Figs 44, 45). Mandíbula unidentada, dente apicalmente castanho escuro, margem superior com cerdas densas e longas. Clípeo com lobo mediano largo, estendendo-se alem do tórulo antenal, margem apical reta com concavidade mediana e cerdas distintamente longas, carena mediana produzida como espinho. Espaço malar reduzido, menor que HE. Fronte polida, com pontos pequenos, rasos e esparsos. Cabeça subquadrada em vista dorsal, LH 1,00x WH, globóide em vista lateral, altura 0,79x LH; vértice convexo e lados paralelos.

Mesossomo (Fig. 46). Disco pronotal subquadrado, margem lateral reta. Mesoscuto triangular com margem anterior côncava. Disco propodeal 1,60x mais longo que largo, constrição anterior acentuada, 0,51x mais largo anterior que posteriormente. Pleurosterno com sulco mediano raso presente somente na porção posterior. Metasterno triangular com sulco mediano progressivamente mais largo. Coxas dilatadas, especialmente mediana. Tíbia anterior não espinhosa, mediana fortemente espinhosa (Fig. 47) e posterior espinhosa.

Metassomo. Distintamente peciolado, pecíolo mais longo que largo. Tergito I abruptamente vertical.

Comentários. Esta é a terceira vez que é reportado um casal de Apenesia em cópula, sendo o primeiro registro por Evans (1969) para Apenesia nitida para a região neotropical, e o segundo por GoRDH (1990) para A. evansi Gordh, 1990 do grupo laevigata para a região australiana. Evans (1969) não descreveu a fêmea de tal modo que não é possível compará-las.

O estudo de casais em cópula representa uma oportunidade ímpar de se estabelecer alguma relação taxonômica entre os sexos.

A fêmea de A. quadrata tem algumas características peculiares que nos chamam a atenção quando comparadas com as fêmeas das demais espécies neotropicais de Apenesia. A cabeça é curta e alta, o que lhe confere aspecto globóide, lembrando o padrão encontrado em alguns gêneros de Sclerodermini, como por exemplo, Nothepyris Evans, 1973 (vide Evans, 1973, fig. 5). O disco propodeal é acentuadamente constrito, fugindo do padrão do gênero e aproximando-se mais do padrão encontrado em Caloapenesia Terayama, 1995 e Acrepyris Kieffer, 1905 (vide chave em LANES \& AzEvedo, 2007). A mandíbula com apenas um dente apical e a concavidade da margem apical do clípeo fazem com que esta fêmea seja facilmente identificada entre as fêmeas das outras espécies de Apenesia.
Material-tipo examinado. Holótipo ơ. BRASIL, Minas Geraes \{=Gerais\}: Diamantina, 14-18.XI.1919, Cornell University Exped[ition] (CUIC \#3881). Genitalia slide HE477. (Figs 25-27).

Material adicional examinado. BRASIL, D[istrito] F[ederal]: Brasília (Reserva Ecológica do IBGE, $15^{\circ} 55^{\prime} 58^{\prime \prime} \mathrm{S}$, $47^{\circ} 51^{\prime} 02$ '” $\mathrm{W}$ ), campo sujo, $1 \mathrm{O}^{7}, 19-26 . X .1979 ; 54 \mathrm{O}^{7}, 05-$ 30.XI.1979; 25 ठో, 09-16.XI.1979; 1 ठ', 16-25.XI.1979; 25 o', 2330.XI.1979; 6 o', 07-14.XII.1979; 4 o', 21-28.XII.1979; 1 o', 0411.I.1980; 2 ठ 18-25.I.1980; 14 Oे, 02-09.II.1980; 1 ठ , 1522.II.1980; 7 ठ , 01-07.III.1980; 1 ठ', 26.III-02.IV.1980; 20 B\&,

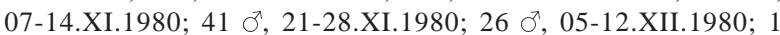

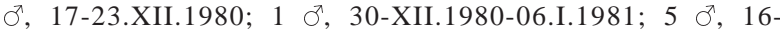

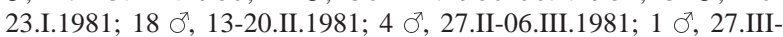
03.IV.1981; 1 ठ’, 24.IV-08.V.1981; 1 ठౌ, 05-17.VI.1981; 1 ठౌ, 916-X.1981; 16 ơ, 19-26.X.1981; 1 ठ', 28.X-11.IX.1981; 6 ơ, 05-

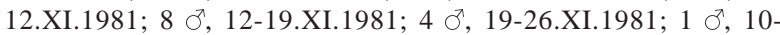
13.XII.1981; 4 ठ', 17-23.XII.1981; 1 ठे, 23-30.XII.1981; 3 ठे, 07-

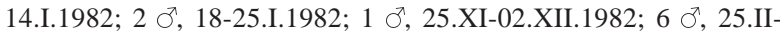
04.III.1982; 4 ठ

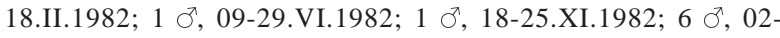
09.XII.1982; 1 ठ , 09-16.XII.1982; 3 वे, 25.XI-02.XII.1982; $2 \sigma^{7}$,

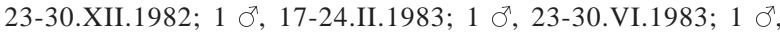
10-17.XI.1983; 2 ठ', 10-17.XII.1983; 12 ठ', 01-07.XII.1983; 2 क, 15-22.XII.1983; 1 ○’, 29.XII.1983-05.I.1984, [armadilha] Janela; $1 \sigma^{2}, 23-30 . X I .1979 ; 1 \sigma^{2}, 24-31 . X .1980 ; 3$ o', 7-14.XI.1980; 7 o, 21-28.XI.1980; 6 ơ, 05-12.XII.1980; 2 ơ, 27.III-03.IV.1981; 5 ơ, 05-12.XI.1981; 5 ơ , 12-19.XI.1981; 4 ơ, 19-26.XI.1981; 10 o', 26.XI-03.XII.1981; 1 o', 29.X-05.XI.1981; 8 o', 03

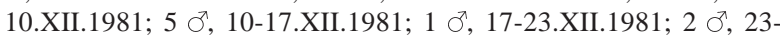
30.XII.1981; 3 ơ, 21-28.I.1982; 4 ठ', 11-18.II.1982, 4 ठ', 25.II04.III.1982; 1 ठ', 01-07-IV-1982; 1 ठे, 07-14.IV.1982; 1 o', 1317.V.1982; 1 ○, 30.IX-07.X.1982; 1 o', 07-14.X.1982; 1 o', 14-

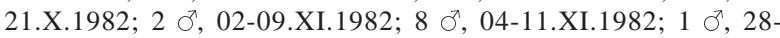
04.XI.1982; 1 ठ', 04-11.XI.1980; 1 ठे, 18-25.XI.1982; 3 ठ', 0916.XII.1982; 5 o , 16-23.XII.1982; 2 ơ, 23-30.XII.1982; 3 क, 24.II-03.III.1983; 1 ơ, 28.IV-05.V.1983; 1 ठ’, 07-14.IX.1983; 1 ơ, 29.III-05.IV.1984, [armadilha] Malaise; campo limpo, 1 ơ 13 20.III.1981; $10^{7}$, 17.VII-03.VIII.1981, [armadilha] Janela; $10^{7}$, 07-14.XI.1980, [armadilha] Malaise; Cerrado, 2 o', 19, 18-

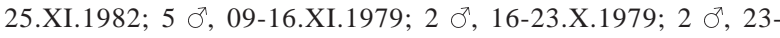
30.XI.1979; 1 ठ’, 02-09.II.1980; 1 ठ’, 01-07.III.1980; 2 ठ’, 2128.VI.1980; 2 ठ', 07-11.XI.1980; 1 ठ’, 21-28.XI.1980; 1 ठ', 30.I-

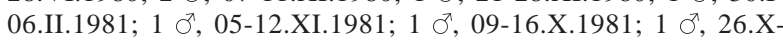
03.XII.1981; 1 ठ 11.XI.1982; 1 ठै, 11-18.XI.1982; 1 ठे, 28-04.XI.1982; 1 ठे, 0209.XII.1982; 2 O , 17-24.II.1983, [armadilha] Janela; 1 o', 09-

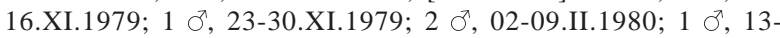
20.II.1981; 1 ठ , 15-22.II.1980; 1 ठ 05-12.XII.1980; 2 ठ , 23-

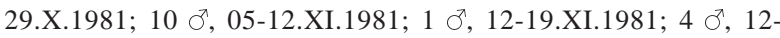

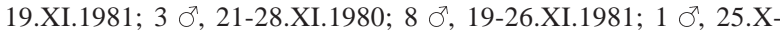
05.XI.1981; 10 o', 03-10.XII.1981; 7 ơ, 26-03.XII.1981; 3 क,

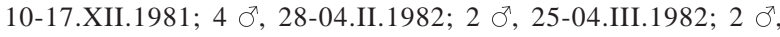

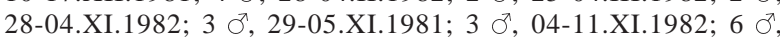
11-18.XI.1982; 1 ơ, 14-21.X.1982; 5 ơ', 02-09.XII.1982; 2 ठ , 09-16.XII.1982; 1 o', 16-23.XII.1982; $2 \sigma^{7}, 18-25 . X I .1982 ; 2$ o, 25.XI-02.XII.1982; 1 o , 27.I-03.II.1983, [armadilha] Malaise; 3

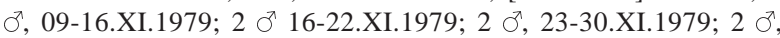
07-14.XII.1979; 1 ठ', 19-26.XI.1981; 1 ơ, 28.X.1982, [armadilha]

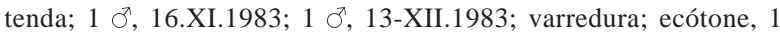

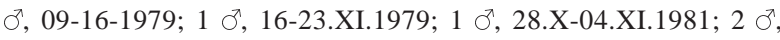
12-19.XI.1981; 1 ơ, 03-10.XII.1981; 1 ơ, 21-28.X.1982; 1 ठ 17.II.1983, [armadilha] Malaise; campo limpo, 1 o , 15-22.II.1980; 1 ठ 17-23.XII.1980; 1 o , 19-26.XI.1981, [armadilha] Malaise; $1 \sigma^{7}$, 01-08.VIII.1980, [armadilha] Janela; beira da mata, $1 \sigma^{7}, 24-$ 31.X.1980, [armadilha] Malaise; brejo, 1 ơ, 11-18.XI.1982; 1 के, 18-25.XI.1982; 1 ơ', 16-23.XII.1982, [armadilha] Malaise; 1 ơ, 17-31.VII.1981, [armadilha] janela; mata, $1 \sigma^{2}, 21-28 . X I .1980 ; 1$ O', 29.X-05.XI.1981; 14.VI.1983; 22-29.XII.1983; 1 o', varredura; 1 ơ, 15.I.1979; 1 ơ, 16.X.1979, [armadilha] Malaise, B. F. S. Dias e outros col. (IBGE). PARAGUAI: Central Capiatá, 2 ơ, 03.X.1993, B. Garcete \& C. Aguilar col. (MNHNP). 


\section{Apenesia quelata sp. nov. (Figs 28-30)}

Descrição. Macho. Comprimento do corpo 4,53 mm. LFW 3,39 mm. Cor. Cabeça e mesossomo pretos, exceto disco pronotal, castanho-escuro; mandíbula, clípeo, antena, pernas e metassomo castanhos; flagelômeros distais mais escuros; palpos e tégula castanho-claros; asas subhialinas.

Cabeça (Fig. 28). Mandíbula com dente inferior distinto e demais fundidos numa lâmina. Clípeo pouco projetado, lobo mediano subangulado, carena mediana elevada e completa (Fig. 29) Quatro primeiros artículos antenais na razão de cerca de 4:1:2:2; artículo III 3,20x mais longo que largo; artículo XI 3,75x mais longo que largo; pubescência flagelar subereta. Olhos glabros. Fronte polida, com pontos pequenos, rasos e esparsos. WH/LH 1,04; WF/HE 1,27; OOL/WOT 1,20; distância do topo do ocelo posterior à crista do vértice $0,54 \mathrm{x}$ DAO; ocelos relativamente próximos; vértice ligeiramente convexo, com cantos arredondados; VOL/HE 0,54.

Mesossomo. Pronoto e mesonoto polidos e pontuados como a fronte. Disco pronotal com carena transversal anterior definida e delgada; depressão transversal posterior completa e rasa. Mesoscuto com notáulice completa, sendo mais delgada na porção anterior; sulco parapsidal incompleto anteriormente. Disco propodeal 1,00x mais longo que largo; carena discal mediana completa e definida; carena transversal posterior presente; triângulo basal definido e o restante do disco polido; declividade estrigulada.

Metassomo. Peciolado. Genitália (Fig. 30). Parâmero não fundido ao basiparâmero, com largura aumentando da base em direção ao ápice, cerca de 4,50x mais largo que base; base sem dobradura ventral; margem interna da região basal com projeção leve; margem apical com depressão pronunciada e regular próxima à margem externa; ápice com margem interna arredondada e cerdas espessas na superfície apical. Basiparâmero amplamente expandido ao longo de sua extensão, exceto próximo à base do parâmero e anel genital, onde ocorre estreitamento. Volsela com cúspide muito expandida; ramo ventral do dígito com base dilatada e ápice gradualmente estreito, com muitas certas na superfície apical. Basivolsela com margem basal retilínea, com cerdas na porção superior. Edeago com dois pares de lobos apicais; par mediano menor que par lateral; lobo lateral espesso em relação ao mediano, levemente voltado para dentro, com ápice arredondado e dividido em duas regiões por septo mediano, com porção mais externa com bastantes pontos; lobo mediano delgado, de ápice pontiagudo.

Material-tipo examinado. Holótipo ơ, BRASIL, Pará: Serra Norte (Estrada Serraria), 07.VII.1984, armadilha suspensa (MPEG). Parátipo: 1 ơ, Pará: Serra Norte (N.1, Serraria, Igarapé Azul), 2024.VI.1985, F. F. Ramos col. (MPEG).

Variações. Comprimento do corpo 4,48 mm; LFW $3,15 \mathrm{~mm}$; parâmero com cerdas espessas na porção mediana; volsela com cerdas na margem interna da volsela.

Discussão. Esta espécie tem o lobo lateral do edeago bipartido, condição que difere esta estrutura daquelas encontradas de todas as espécies conhecidas do grupo de espécies nitida. O padrão básico do parâmero assemelha-se ao encontrado em algumas espécies conhecidas, mas em A. quelata sp. nov. existe uma depressão pronunciada e regular próxima a margem externa. Além disso, a basivolsela apresenta margem basal retilínea, dessa forma tais condições tornam essa espécie completamente distinta das demais espécies conhecidas referentes ao grupo.

Etimologia. O epíteto específico refere-se ao formato de quela do ápice do lobo lateral do edeago.

Distribuição. Brasil (Pará).

\section{Apenesia serrulata Azevedo \& Batista, 2002}

(Figs 31-33)

Esta espécie foi registrada para o estado do Acre no Brasil por AzEvedo \& BATISTA (2002) e agora é citada pela primeira vez para o Equador (Napo e Sucumbios).

Variações. Clípeo com lobo mediano subangulado, carena mediana ausente; pubescência antenal subereta, com algumas cerdas eretas e de comprimento maior; notáulice completa anteriormente (com uma linha fraca atingindo a margem posterior); disco pronotal com carena discal mediana completa, carena transversal bem definida; asa subhialina; margem apical do parâmero com profundidade mais pronunciada.

Material-tipo examinado. Holótipo $0^{7}$. BRASIL, Acre: $\mathrm{P}[\operatorname{ar}] \mathrm{q}[\mathrm{u}] \mathrm{e}$ Nac[ional da] Serra [do] Divisor, [ponto] sul 6, 1819.III.1997, arm[adilha] Malaise, E. F. Morato col. (UFES) (Figs 31-33)

Material adicional examinado. EQUADOR, Sucumbios: (Napo River, Sacha Lodge, $0^{\circ}$ 5' S, 76 5' W, 290 m), 4 o’, M[alaise] T[rap]; $10^{\circ},\left(0^{\circ} 30^{\prime} \mathrm{S}, 76^{\circ} 30^{\prime} \mathrm{W}, 225 \mathrm{~m}\right), 20-30 . I X .1994$, M[alaise T[rap]; 4 on, 24.III.1994, M[alaise] T[rap]; 1 o, 13-23.IV.1994, M[alaise] T[rap]; 1 ơ, 03-13.VIII.1994, Malaise; 3 o', 12.VI.1995, M[alaise] T[rap]; 3 o, 14-24.V.1994 M[alaise] T[rap], P. Hibbs col. (CNCI); Napo: Limnococha (50 m), 6 o', 15-28.IV.1976, S. \& J. Peck col. (CNCI); (Sumbios River, Sacha Lodge, $0^{\circ} 5$ 'S, 76 $6^{\circ}$ ' W, $270 \mathrm{~m}), 1 \mathrm{o}^{2},(\mathrm{CNCI})$

\section{Apenesia trivisa sp. nov. (Figs 37-39)}

Descrição. Macho. Comprimento do corpo 5,92 mm. LFW 4,30 mm. Cor. Cabeça e mesossomo pretos; mandíbula, antena, pernas e tégula castanhos; flagelômeros distais mais escuros; palpos castanhoclaros; asas subhialinas.

Cabeça (Fig. 37). Mandíbula com dente inferior distinto e demais fundidos numa lâmina (Fig. 38). Clípeo pouco projetado, lobo mediano estreitamente truncado, carena mediana pouco elevada e incompleta. Quatro primeiros artículos antenais na razão de cerca de 4:1:2:2; artículo III 3,00x mais longo que largo; artículo XI 2,70x mais longo que largo; pubescência flagelar subereta. Olhos glabros. Fronte polida, com pontos pequenos, rasos e esparsos. WH/LH 1,08; WF/HE 1,42; OOL/WOT 1,36; distância do topo do ocelo posterior à crista do vértice 0,41x DAO; ocelos relativamente separados; vértice ligeiramente convexo com cantos arredondados; VOL/HE 1,00.

Mesossomo. Pronoto e mesonoto polidos e pontuados de maneira semelhante à fronte. Disco pronotal com carena transversal anterior definida e depressão transversal posterior incompleta. Mesoscuto com notáulice completa, sendo mais delgada na porção anterior; sulco parapsidal incompleto anteriormente. Disco propodeal 1,07x mais longo que largo; carena discal 


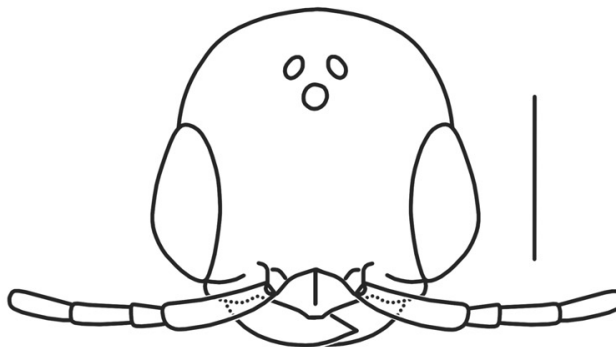

20

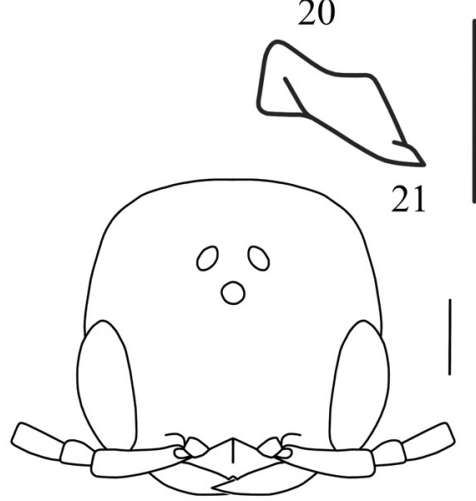

24
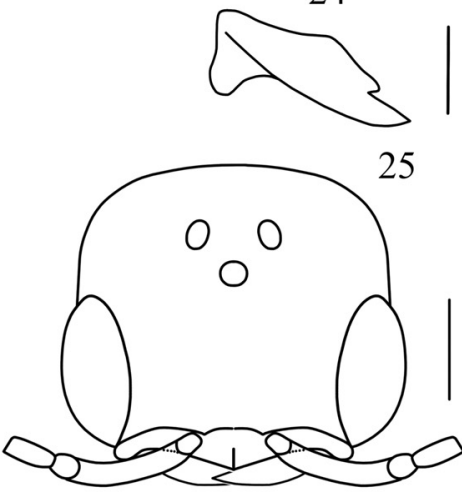

28

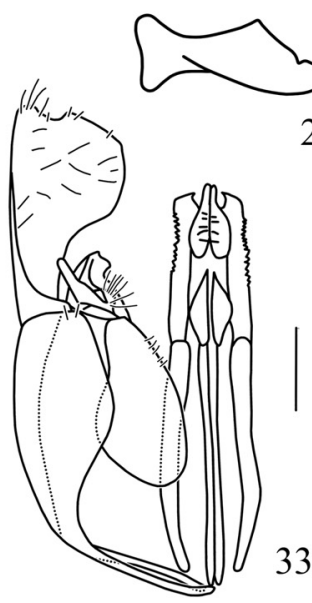

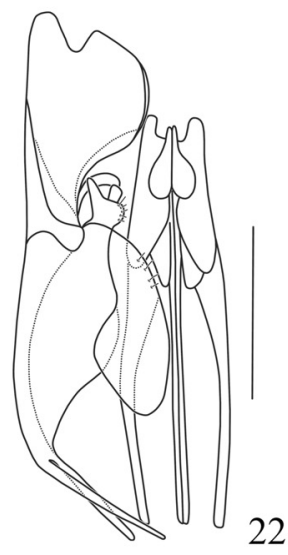
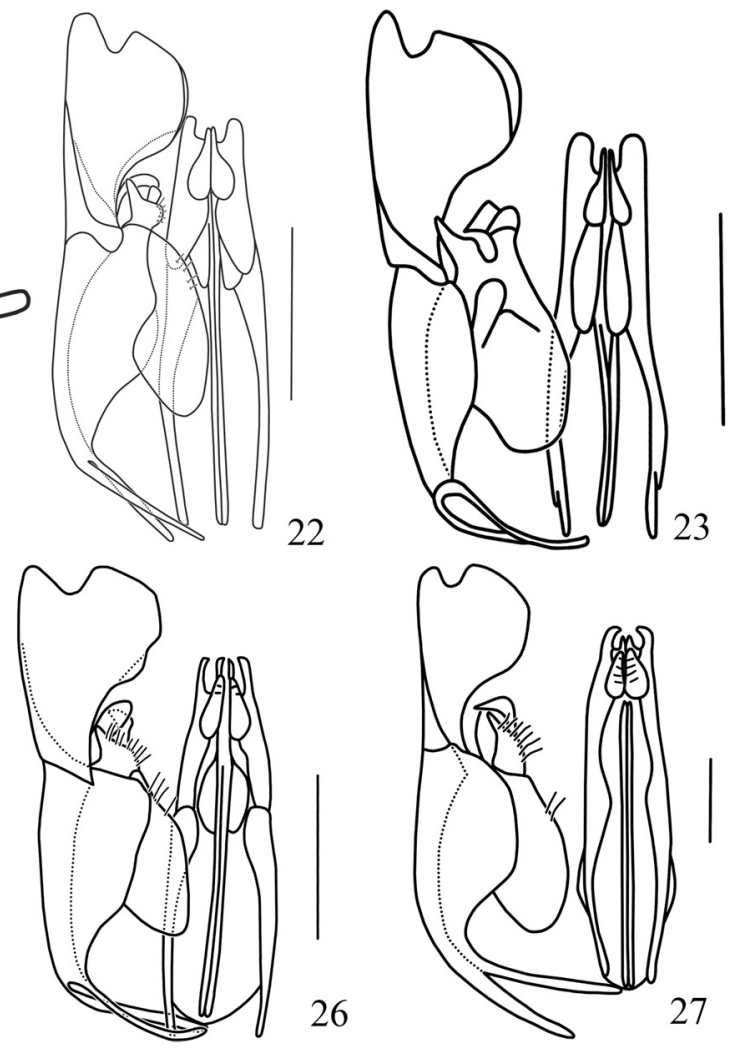

26
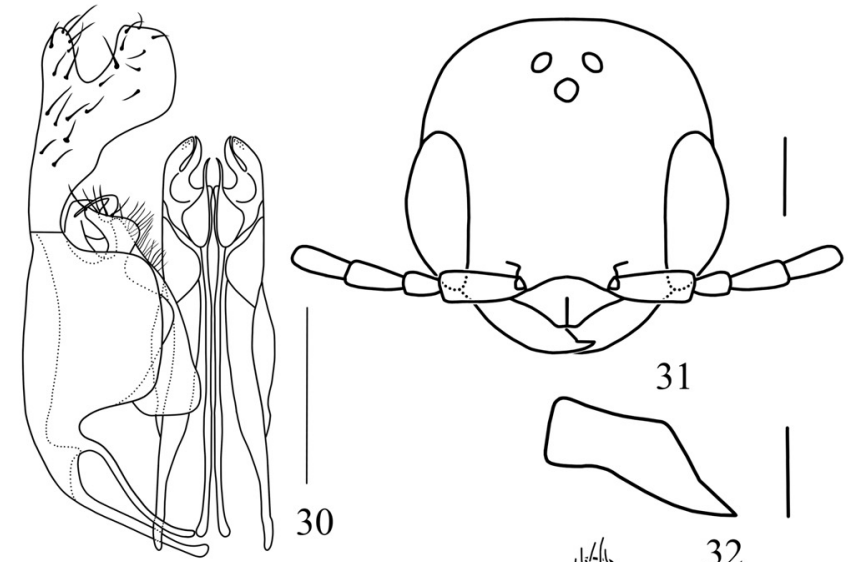

30
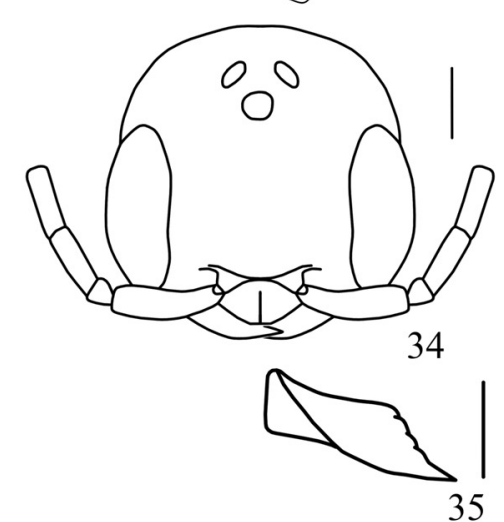

35

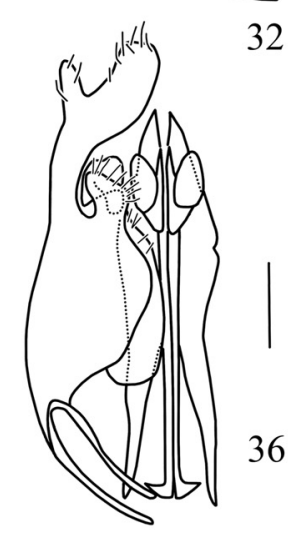

Figuras. 20-36. Apenesia paraensis Kieffer, 1910, macho: 20, cabeça, dorsal; 21, mandíbula, frontal; 22, genitália, ventral. A. truncaticeps (Kieffer, 1910), holótipo: 23, genitália, ventral. A. quadrata Evans, 1963, macho: 24, cabeça, dorsal; 25, mandíbula, frontal; 26, genitália, ventral. A. laticeps Evans, 1963, holótipo: 27, genitália, ventral. Apenesia quelata sp. nov., macho: 28, cabeça, dorsal; 29, mandíbula, frontal; 30, genitália, ventral. A. serrulata Azevedo \& Batista, 2002, macho: 31, cabeça, dorsal; 32, mandíbula, frontal; 33, genitália, ventral. A. subangulata Azevedo \& Batista, 2002, macho: 34, cabeça, dorsal; 35, mandíbula, frontal; 36, genitália, ventral. Escalas: $0,25 \mathrm{~mm}$. 
mediana completa e definida; carena transversal posterior distinta; triângulo basal definido e restante do disco polido; declividade estrigulada.

Metassomo peciolado. Genitália (Fig. 39). Parâmero não fundido ao basiparâmero, com largura aumentando da base em direção ao ápice; base com dobradura ventral; margem apical com depressão regular próxima à margem externa; margem interna do ápice retilínea com cantos arredondados e cerdas na superfície apical. Basiparâmero amplamente expandido próximo à base do parâmero e estreitando-se em direção ao anel genital. Volsela com cúspide pouco expandida; ramo ventral do dígito com base dilatada e ápice gradualmente estreito, com muitas cerdas na superfície apical. Basivolsela com margem basal estreitamente arredondada, com cerdas na porção superior. Edeago com dois pares de lobos apicais; par lateral formado por três estruturas - placa ventral, placa mediana e placa dorsal; placa ventral expandida e arredondada apicalmente, maior do que as demais placas e lobo mediano; placa mediana com ápice pontiagudo, voltado para dentro; placa dorsal truncada apicalmente, menor que demais placas e lobo mediano, lobo mediano delgado, de ápice arredondado.

Material-tipo examinado. Holótipo ơ, TRINIDAD, $19 \mathrm{~km}$ $\mathrm{N}$ Arima: Lalaja Trace (Montane rain for[est], $650 \mathrm{~m}$ ), 0824.VI.1993, F[light] I[nterception] T[rap], S. \& J. Peck col. (CNCI). Parátipos: TRINIDAD, mesma localidade do holótipo, 4 o , 08 24.VI.1993; 15 ơ 08-14.VI.1993, 93-20; 7 ơ, 24.VI-7.VII.1993, F[light] I[nterception] T[rap], S. \& J. Peck col., 93-59 (CNCI); 16 $\mathrm{km} N$ Arima: Andrews Trace (620 m, up[per] montane rain for[est]), 7 ơ, 07-24.VI.1993; 1 ơ', 24.VI-07.VII.1993, F[light] I[nterception] T[rap], S. \& J. Peck col. 93-61 (CNCI); 8 km N Arima: Simla Res[erva] S[an]ta (trop[ical] for[est], $240 \mathrm{~m}$ ), 1 o o $^{2}$ 06-10.VI.1993, M[alaise] T[rap], 93-10 ; (lower montane rain for[est], $260 \mathrm{~m}$ ), 1 o', 14-24.VI.1993, F[light] I[nterception] T[rap] ; 260m , 1 o", 24.VI-8.VII.1993, S. \& J. Peck col. (CNCI); 13 km S Arima, 2 km N Talparo: Quesnell Farm (rain for[est], 50 m), 4 o', 12-22.VI.1993; 3
07, 22.VI-8 VII.1993, F[light] I[nterception] T[rap], S. \& J. Peck col. (CNCI); Curepe: 1 on, 05-11.XII.1977; 1 o', 05-08.XII.1977, M[alaise] T[rap], W. R. Mason col.; $1 \delta^{7}, 16$. II.1978, M[alaise] T[rap]; 1 o', 19-29.III.1979, M[alaise] T[rap], F. D. Bennett col.; 1 o 09.XI-29.XII.1979, P[itfall] T[rap] (CNCI); Maracas: Valley above Loango Village (montane rain. for.[est], $600 \mathrm{~m}$ ), $5 \mathrm{o}^{2}, 09$ 22.VI.1993; 1 ○', 22.VI-06.VII.1993, F[light] I[nterception] T[rap], S. \& J. Peck col., 93-43 (CNCI); Simla: n[ea]r Arima (rain for[est], $250 \mathrm{~m}), 1 \mathrm{O}^{7}$, 25.XI-31.XII.1997, W. R. M. Mason col. (CNCI); 11 km SE Arima: Arena For[est] Res[erve], (rain for[est], $80 \mathrm{~m}$ ), $2 \mathrm{O}^{2}$ 22.VI-08.VII.1993, F[light] I[nterception] T[rap], S. \& J. Peck col. (CNCI); Morne Blue: 2700', 4 O', 17.VIII.1969, H. \& A. Howden col. (CNCI).

Variações. Comprimento do corpo 5,20-6,77 mm; volsela com margem interna com cerdas longas.

Discussão. Esta espécie apresenta edeago com lobo lateral formado por três estruturas distintas, a saber: placa ventral, placa mediana e placa dorsal, condição que difere esta estrutura daquelas observadas em todas as outras espécies conhecidas do grupo de espécies nitida. $\mathrm{O}$ padrão básico do parâmero assemelha-se ao encontrado em algumas espécies conhecidas, mas em A. trivisa sp. nov. o parâmero possui ápice fortemente expandido e na base uma distinta dobra ventral. Dessa forma, tais condições tornam essa espécie completamente distinta das demais espécies conhecidas do grupo.

Etimologia. O epíteto específico refere-se ao lobo lateral formado por três peças dispostas ventral, mediana e dorsalmente.

Distribuição: Trinidad.

\section{Apenesia williamsi Evans, 1966}

(Figs 40-43)

Esta espécie foi registrada para os estados do Mato Grosso e São Paulo no Brasil por Evans (1966) e agora é citada pela primeira vez para o Distrito Federal (Brasil).

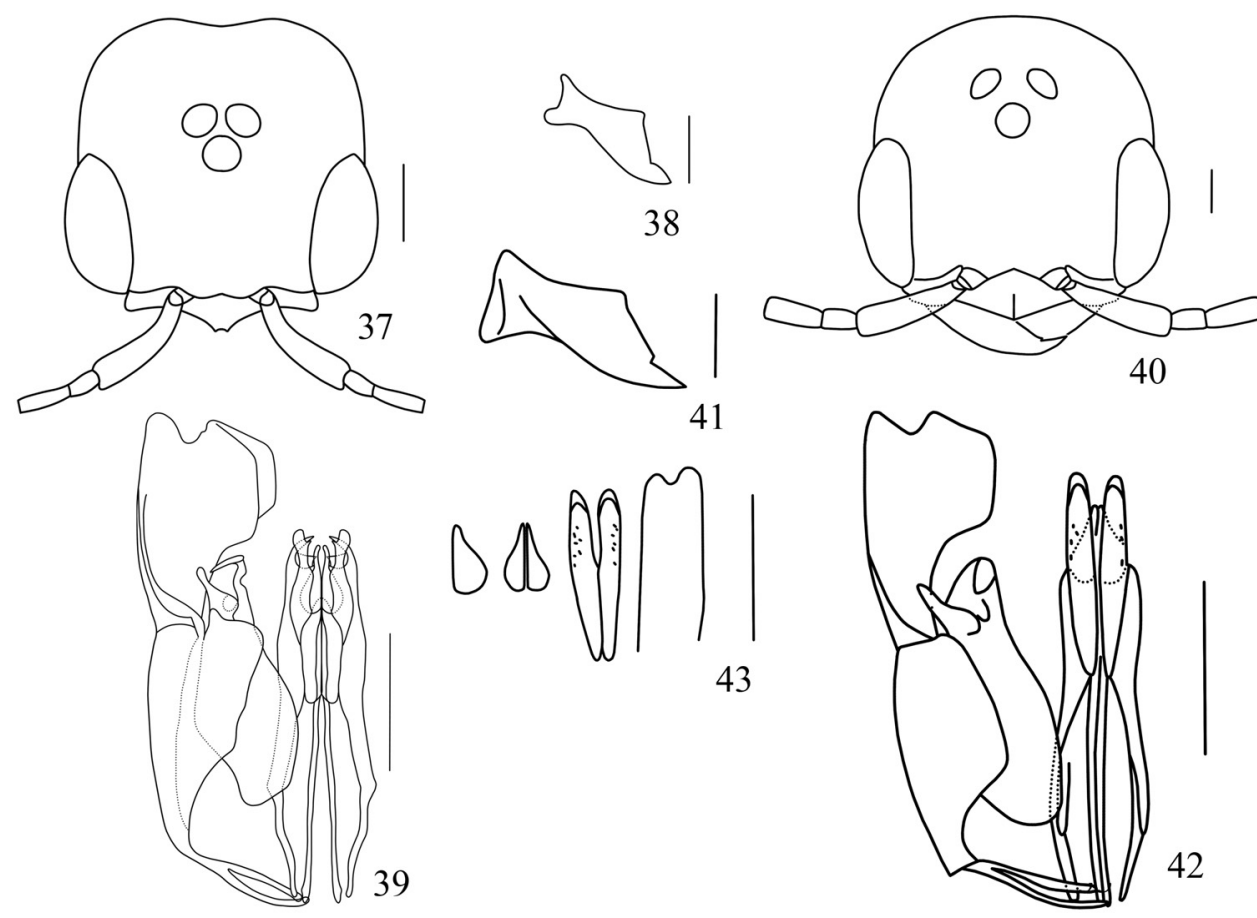

Figuras. 37-43. Apenesia trivisa sp. nov.: 37, cabeça, dorsal; 38, mandíbula, frontal; 39, genitália, ventral. A. williamsi Evans, 1966: 40, cabeça, dorsal; 41, mandíbula, frontal; 42, genitália, ventral; 43, lobos apicais do edeago, ventral. Escalas: 0,25 mm. 

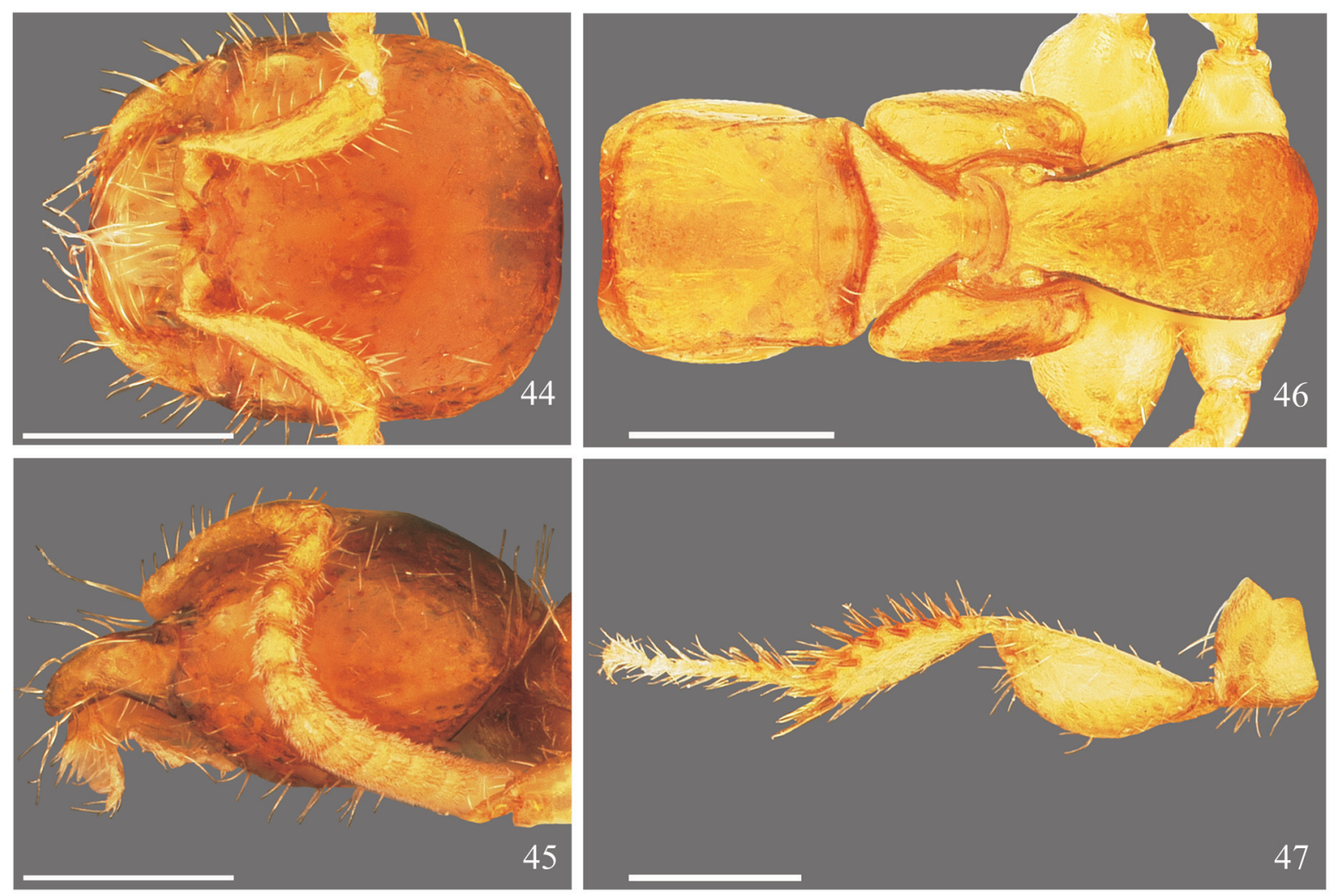

Figuras. 44-47. Apenesia quadrata Evans, 1963, fêmea: 44, cabeça, dorsal; 45, cabeça, lateral; 46, mesossomo, dorsal; 47, perna mediana, dorsal. Escalas: 0,30 $\mathrm{mm}$.

Variações. Mesoscuto com notáulice completa; disco propodeal com carena discal mediana que varia de distintamente incompleta em alguns espécimes a completa em outros, mas nunca ultrapassando a carena transversal posterior.

Comentários. Segundo Evans (1963), os lobos medianos do edeago seriam fundidos numa placa, mas neste trabalho percebeu-se que esses lobos são pequenos e completamente separados e ainda que os lobos laterais parecem ser formados por três partes. Além disso, observou-se que o edeago apresenta cerdas na margem interna da volsela e porção superior da basivolsela. A depressão transversal posterior no disco pronotal apresenta-se muito rasa, como uma linha na vista dorsal.

Material-tipo examinado. Holótipo ơ. BRASIL, [São Paulo]: Campinas, III.1924, F. X. Williams col. (BPBM) (Figs 40-43).

Material adicional examinado. BRASIL, Mato Grosso: Campo Grande, 1 Ơ, 31.XI.1952, Moacir Alvarenga col. (MNRJ); D[istrito] F[ederal]: Brasília (Reserva Ecológica do IBGE,

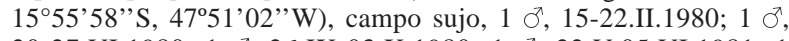
20-27.VI.1980; 1 ठ', 26.IX-03.X.1980; 1 ठ', 22.V-05.VI.1981; 1 ơ , 02-09.X.1981; 1 ठ', 09-24.VI.1982; 2 o', 16-23.XII.1982; 1 o', 29.XII.1982, [armadilha] Malaise; campo limpo, 1 ơ, 04-11.I.1980;

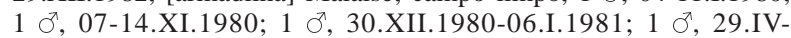

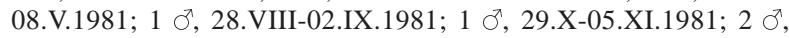
04-11.II.1982; 1 ठ์, 11-18.III.1982; 1 ठ', 18-25.III.1982; 1 ठ , 0519.VIII.1982; 1 ơ, 07-14.X.1982; 1 o', 23-30.XII.1982; 1 o', 2027.I.1983, [armadilha] Malaise; 1 ơ, 09-16.XI.1979; 3 ơ, 1320.III.1981; 2 ठ', 10-24.VI.1981; 1 ठ , 22.V-05.VI.1981; 1 ठ", 25.III-01.IV.1982; 1 ठ $\sigma^{2}, 15-29 . I V .1982 ; 1$ ठ 09-16.XI.1982, [armadilha] janela; brejo, $2 O^{\top}, 10-24 . I V .1981 ; 1$ ơ, 08-22.VII.1982, [armadilha] Malaise; B. F. S. Dias col. (IBGE);
São Paulo: Araras, 1 o', 30.VII.1981, L. B. Lozada col. (MNRJ); $1 \sigma^{\top}, 26$. V.1983, rede entomológica, L. B. L. Marchetti col. (MNRJ).

Agradecimentos. A Daniele Mugrabi, Diego Barbosa, Fernanda Gobbi, Isabel Alencar, Geane Lanes, Lidiana Zamprogno pela ajuda na análise dos caracteres; aos respectivos curadores das coleções citados no texto pelo empréstimo do material biológico; ao $\mathrm{CNPq}$ pela concessão da bolsa de iniciação científica do primeiro e segundo autores e de produtividade em pesquisa do terceiro, e pelo apoio financeiro processos $n^{\circ} 303216 / 2004-2$ e $n^{\circ} 306331 /$ 2007-70, ao Programa Taxonomia (\#563953/05-5) e à FAPES processo $n^{\circ} 45429065 / 09$.

\section{REFERÊNCIAS BIBLIOGRÁFICAS}

Azevedo, C. O. \& Batista, M. L. 2002. New species of Apenesia (Hymenoptera, Bethylidae) from Parque Nacional da Serra do Divisor, Acre, Brasil. Revista Brasileira de Entomologia 46:25-32.

CorrêA, M. S. \& Azevedo, C. O. 2006. O gênero Apenesia (Hymenoptera, Bethylidae) na Mata Atlântica: notas e descrição de sete espécies novas. Revista Brasileira de Entomologia 50:439-449.

DallwitZ, M. J. 1980. A general system for coding taxonomic descriptions. Taxon 29:41-46.

Dallwitz, M. J.; PAine, T. A. \& Zurcher, E. J. 1993. User's guide to the DELTA System: a general system for processing taxonomic descriptions. 4. ed. Disponível em: <http:// biodiversity.uno.edu/delta/>. Acesso em: 10.01.2010.

_.User's guide to the DELTA Editor. Disponível em: <http:/ /biodiversity.uno.edu/delta/>. Acesso em: 10.01.2010.

Evans, H. E. 1963. A revision of the genus Apenesia in the Americas (Hymenoptera, Bethylidae). Bulletin of the Museum of Comparative Zoology 130:249-359.

1966. Further studies on Neotropical Pristocerinae (Hymenoptera, Bethylidae). Acta Hymenopterologica 2:99-117. 
1969. Phoretic copulation in Hymenoptera. Entomological News 80:113-124.

1973. Further studies on South American Bethylidae (Hymenoptera). Proceedings of the Entomological Society of Washington 75:194-204.

Gordh, G. 1990. Apenesia evansi sp. n. (Hymenoptera, Bethylidae) from Australia with comments on phoretic copulation in bethylids. Journal of the Australian Entomological Society 29:167-170.

HARRIS, R. A. 1979. A glossary of surface sculpturing. Occasional Papers in Entomology 28:1-31.
KiefFer, J. J. 1910. Description de nouveaux Béthylides. Annales de la Société Entomologique de France 79:31-56.

Lanes, G. O. \& Azevedo, C. O. 2004. New species and notes on Apenesia (Hymenoptera, Bethylidae) from Brazilian Amazon. Zootaxa 79:1-16.

2007. Redescription and placement of the Oriental Scaphepyris rufus Kieffer (Hymenoptera, Bethylidae). Zootaxa 1654:55-60.

Ogloblin, 1938. Descripciones de Bethylidae y Dryinidae de las colecciones del Museo Argentino de Ciencias Naturales. Anales del Museo Argentino de Ciencias Naturales 40:35-48. 